\title{
The Study of Several Applicable Treatments for Serving Butterfly Pea Flower Drinks
}

\author{
Jesslyn Sofyan, Tabligh Permana, Abdullah Muzi Marpaung* \\ Food Technology Department, Swiss German University, Tangerang, Indonesia \\ *Corresponding author. Email: abdullah.muzi@sgu.ac.id
}

\begin{abstract}
A wide range of serving methods of butterfly pea flower drinks are available in practice. Three typical variables in the serving method are studied in this research. They are pre-treatment of the petal before extraction (fresh, refrigerated for two days, dried at $45^{\circ} \mathrm{C}$ for 48 hours), the method of extraction (brew in hot water $100^{\circ} \mathrm{C}$, brew in hot water $75^{\circ} \mathrm{C}$, boil in water) and the addition of lime juice (no lime, $3.5 \mathrm{~g}$ lime added before extraction, $3.5 \mathrm{~g}$ lime added after extraction). The volume of water is $125 \mathrm{ml}$, the weight of the butterfly pea flower is $0.1885 \mathrm{~g}$ dry basis, and the time of extraction is 15 minutes. Design Expert ${ }^{\circledR}$ software is applied to analyze the dependent variables or responses (color intensity, violet index, browning index, total anthocyanin, and antioxidant activity) of the drinks. In general, a linear model with interactions of two variables is the fittest model to describe the effect of the three variables to the responses. The addition of lime is the main variable to affect the violet index and antioxidant activity. The method of extraction is the main factor affecting the color intensity and total anthocyanin. In addition, fresh petals result in better quality of butterfly pea drinks than refrigerated and dried petals. The best set of variables to yield the highest antioxidant activity, relatively high anthocyanin content, and relatively high color quality of the drinks is the fresh petal, boil in water, and lime added before extraction. The $95 \%$ predicted intervals of total anthocyanin and antioxidant activity of the drinks are 8.26 to $9.77 \mathrm{mg} / \mathrm{g}$ petal on a dry basis and 70.33 to $82.49 \%$ inhibition, respectively. Meanwhile, the color of the drinks is deep purple (color intensity 2.73 to 3.55 , violet index $0.75-1.33$ ) with relatively low browning index $(0.17$ to 0.49 ).
\end{abstract}

Keywords: Anthocyanin, Antioxidant activity, Butterfly pea flower, Functional drinks.

\section{INTRODUCTION}

Butterfly pea (Clitoria ternatea L.) is one of the plants that all parts have health benefits to our body [1]. Its flower contains poly acylated anthocyanins called ternatins [2] and flavonol glycosides [3]. They provide positive health effects, like antioxidants, antidiabetic, antiobesity, anti inflammation, anticancer, antihyperlipidemic, anti asthma etc [1].

As the butterfly pea flower is known to have good functional benefits, the popularity of butterfly pea drinks has increased, recently. There were various ways to extract the bioactive compound from a plant source to be served as a functional drink. Brewing and boiling were the most common methods used in daily life. Different extraction methods could give an impact to the characteristic of the product, especially in the anthocyanin content [4]. Among factors in extraction, temperature is reported as one of the most influential factors $[4,5]$.
People usually use fresh or dried flowers or leaves to make a functional drink at home. The delayed use of fresh materials by storing them in a refrigerator for a certain time was also found. The direct or indirect use of the butterfly pea flower potentially affects the bioactive compound, especially the anthocyanin content. Several studies reported that drying may reduce the bioactive compound and antioxidant activity $[6,7]$.

To certain people, the butterfly pea drink is almost tasteless, or the taste is still acceptable. However, certain other people detect an unpleasant taste in the drinks. Some ingredients are usually added to cover the taste. One of the most common of them is lime. The addition of lime reduces the $\mathrm{pH}$ of the drinks. As the decrease of the $\mathrm{pH}$, the antioxidant activity and anthocyanin stability may be affected. In general, anthocyanins show higher stability at a lower $\mathrm{pH}[4,8]$. Additionally, lime is also a great source of phytochemicals like ascorbic acid and flavonoids that are widely known as antioxidants. 
Furthermore, the lime addition could produce a synergistic effect to some herbal medicines [9].

Other than the functional effect, butterfly pea drinks are blue color drinks. The color quality of the drinks, such as color intensity, violet index, and browning index [8] may be affected by the way of the serving of butterfly pea drinks.

Yet, there is almost no information related to the impact of pre-treatment of the petal before extraction, method of the extraction, and lime added to the performance of butterfly pea drinks. The only associated study was the observation of the increase of color intensity and total anthocyanin during maceration of butterfly pea flowers in water [10]. Thus, there was no scientific practical guidance for people to serve the butterfly pea drinks. This research aimed to set the application of the pre-treatment of butterfly pea flower, the extraction method at home, and lime added to yield the highest anthocyanin content and antioxidant activity with the acceptable color quality

\section{MATERIALS AND METHOD}

\subsection{Materials}

The fresh butterfly pea flower obtained from a private garden located in Pondok Kacang Barat, Tangerang, Banten, Indonesia. The petal part separated from the sepal. The petals are divided into three groups. First, fresh petals are directly used to make butterfly pea drinks (PF). Second, fresh petals are packed in HDPE plastic and stored in a refrigerator $\left(4-5^{\circ} \mathrm{C}\right)$ for two days (PR). Third, fresh petal hot-air dried at $45^{\circ} \mathrm{C}$ for 48 hours. The dried petals are packed in HDPE plastic and stored in a freezer $\left(-20^{\circ} \mathrm{C}\right)(\mathrm{PD})$. The drinking water (Aqua $\left.{ }^{\circledR}\right)$ to extract anthocyanin from the butterfly pea flower purchased from a local market in Tangerang, Banten, Indonesia. The lime obtained from traditional markets in Cideng, Gambir, Jakarta, Indonesia. The chemicals were hydrochloric acid, ethanol (Merck, Germany), and 2,2Diphenyl-1-Picrylhydrazyl hydrate (DPPH) (SigmaAldrich, Germany). All chemicals were analytical grade

\subsection{Procedures for Preparation of the Butterfly Pea Flower Beverage}

In general, the preparation of butterfly pea drinks mimicked the common practice at home. The basic formula of butterfly pea drinks consists of $125 \mathrm{ml}$ of water, $0.1885 \mathrm{~g}$ (dry basis $-\mathrm{db}$ ) butterfly pea petal and 0 or $3.5 \mathrm{~g}$ lime juice. The basic procedure to prepare the drinks was simply by immersing the flower in the water for 15 minutes. The lime juice is added before immersion or after 15 minutes of immersion. After immersion, the liquid part separated from the residual petal by filtration with tofu cloth followed by filtration through a filter paper (Whatman $40-8 \mu \mathrm{M}$ ).
There were three factors studied to find the best procedure to prepare butterfly pea drinks. First, the pretreatment of butterfly pea petals (PF, PR, and PD). The average moisture content (by gravimetry) of dried petals was $22.42 \%$. Second, the method of extraction (brewed in hot water $100^{\circ} \mathrm{C}-\mathrm{EH}$, brewed in dispenser hot water $75^{\circ} \mathrm{C}$ - ED, and boiled in water in pan - EB). Third, the addition of lime juice $(0 \mathrm{~g}$ - PO, 3.5g lime juice before extraction - PLB, $3.5 \mathrm{~g}$ lime juice after extraction - PLA). In other words, the experimental design of the research was three-level factorial design with three factors.

The experimental design was arranged with the help of Design-Expert ${ }^{\circledR}$ software version 7.0.0. (Stat-Ease Inc.). In total, 27 combinations of butterfly pea drinks were made in this research. To each butterfly pea drink, the analyses of color quality (color intensity, violet index, and browning index) and functional properties (total anthocyanin and antioxidant activity) were applied.

\subsection{Evaluation of Color Quality}

Color quality of an anthocyanin source extract is often determined by its color intensity $(\mathrm{CI})$, violet index (VI) and browning index (BI) [8]. They were determined spectrophotometrically by a UV-Vis Spectrophotometer (T60 visible PG Instrument, Leicestershire, United Kingdom).

CI calculated following the method that specifically developed for butterfly pea flower extract [11] with modification (Equation 1).

$C I=\left(A_{\lambda \max }-A_{700}\right)+\left(A_{\lambda \text { peak }}-A_{700}\right)+\left(A_{\lambda \text { shoulder }}-A_{700}\right)$

Note: $A_{\lambda \max }$ is the absorbance at $\lambda_{\max }, A_{\lambda \text { peak }}$ is the absorbance at $\lambda_{\text {peak }}, A_{\lambda \text { shoulder }}$ is the absorbance at $\lambda_{\text {shoulder }}$. All are in the visible region. $\mathrm{A}_{700}$ is the absorbance at wavelength $700 \mathrm{~nm}$ for haze correction.

VI is widely being used to characterize the anthocyanin extracts for estimating the shade or hue as shown in Equation 2 [8].

$\mathrm{VI}=\left(\mathrm{A}_{580}-\mathrm{A}_{700}\right) /\left(\mathrm{A}_{520}-\mathrm{A}_{700}\right)$

Note: $\mathrm{A}_{580}$ is the absorbance at $580 \mathrm{~nm}$ which provides purple blue color intensity. $\mathrm{A}_{520}$ is the absorbance at 520 $\mathrm{nm}$ and provides the red color intensity.

BI or usually known as brown color purity, is a measurement of the browning compounds changes and become the most common sugar browning indicators in food products. The yellow brown color is probably contributed by the development of brown pigment through oxidation or by the form of cis-Chalcone and trans-Chalcone. It is an indirect method for monitoring the anthocyanin degradation (Equation 3).

$\mathrm{BI}=\left(\mathrm{A}_{420}-\mathrm{A}_{700}\right) /\left(\mathrm{A}_{\lambda \max }-\mathrm{A}_{700}\right)[11]$

Note: $\mathrm{A}_{420}$ is the absorbance at $420 \mathrm{~nm}$. 


\subsection{Total Anthocyanin Determination}

The measurement of total anthocyanin (TA) applied to the butterfly pea drinks and fresh butterfly pea flower. The extraction of all anthocyanin from the petal was by maceration in $0.1 \% \mathrm{HCl}(\mathrm{v} / \mathrm{v})$ in ethanol with a ratio of 1:1 [12]. 1.85 gram of fresh petal macerated in $100 \mathrm{ml}$ solvent for approximately $24 \mathrm{~h}$ in room temperature without any exposure to light. The mixture is filtered by tofu cloth and filter paper (Whatman $40-8 \mu \mathrm{M}$ ). The residual petal re-macerated in the solvent for another 24 hours until colorless solvent obtained

Total anthocyanin determined by the single $\mathrm{pH}$ method [13]. One ml sample adjusted to reach $\mathrm{pH} 1$ by the addition of $\mathrm{HCl} 0.1 \mathrm{M}$. The absorbance of diluted sample measured at the highest peak in visible region (absorbance at $\lambda_{\max }$ ) and at $700 \mathrm{~nm}\left(\mathrm{~A}_{700}\right)$. The TA calculated by the equations below (Equation 4-6).

$A=\left(A_{\lambda \max }-A_{700}\right)$

$\mathrm{TA}_{\mathrm{mg} / \mathrm{ml}}=(\mathrm{A} \times \mathrm{MW} \times \mathrm{DF}) /(\mathcal{E} \times 1)$

$\mathrm{TA}_{\mathrm{mg} / \mathrm{g}}=\mathrm{TA}_{\mathrm{mg} / \mathrm{ml}} \times \mathrm{V} /(\mathrm{W} \times 1-\mathrm{MC})$

Note: $\mathrm{TA} \mathrm{mg} / \mathrm{ml}$ is total anthocyanin in $\mathrm{mg} / \mathrm{ml}$ extract, $\mathrm{TA}_{\mathrm{mg} / \mathrm{g}}$ is total anthocyanin in $\mathrm{mg} / \mathrm{g}$ petal in dry basis (db), MW is the molecular weight of delphinidin-3glucoside $(\mathrm{g} / \mathrm{mol})=465 \mathrm{~g} / \mathrm{mol}$, DF is the dilution factor, $\varepsilon$ is the molar absorptivity of delphinidin-3-glucoside (L. $\left.\mathrm{cm}^{-1} \cdot \mathrm{mol}^{-1}\right)=29000$, and $\mathrm{l}$ is the cuvette length, $\mathrm{V}$ is the volume of extract $(\mathrm{ml}), \mathrm{W}$ is the weight of petal $(\mathrm{g})$, $\mathrm{MC}$ is the moisture content of petal (\%).

\subsection{Analysis of Antioxidant Activity}

The antioxidant activity was assessed by using 2,2diphenyl-1-picrylhydrazyl (DPPH) [14]. The DPPH stock solution was done by diluting $10 \mathrm{mg}$ of DPPH powder $(\mathrm{Mr}=394.33)$ in $100 \mathrm{ml}$ ethanol $(96 \% \mathrm{~V} / \mathrm{V})$ and resulting in $250 \mu \mathrm{M}$ DPPH stock solution. Then, DF 6 of the sample was prepared by diluting $100 \mu \mathrm{L}$ of sample extract with $500 \mu \mathrm{L}$ of water (solvent) and homogenized with $600 \mu \mathrm{L}$ of DPPH stock solution in a cuvette and incubated in a dark chamber for 30 minutes at room temperature without any exposure of light. Similar procedure was repeated for control and blank solution by replacing sample extract with ethanol and water with the ratio of $1: 1$, respectively for control and blank solution. The absorbance values were then measured at $517 \mathrm{~nm}$ with UV-vis spectrophotometer and compared with a control without extract and the assays were carried out in triplicate. The inhibition percentage of free radical DPPH was determined using the following formula (Equation 5).

\%Inhibition $=\left(\mathrm{A}_{c}-\mathrm{A}_{\mathrm{s}}\right) / \mathrm{A}_{\mathrm{c}} \mathrm{X} 100 \%$

Note: $A_{c}$ is the absorbance of control. $A_{s}$ is Absorbance of sample extract.

\subsection{Statistical Analysis}

A response (dependent variable) can be seen as the function of factors (independent variables) studied. A three levels factorial design with three factors is suitable for determining the significance of the relationship of a response and factors through three types of linear model: linear without interaction, linear with interaction of two factors, and linear with interaction of three factors. The equations of the model are stated as follows.

$$
\begin{aligned}
& Y=A+B+C \\
& Y=A+B+C+A B+A C+B C \\
& Y=A+B+C+A B+A C+B C+A B C
\end{aligned}
$$

Note: $\mathrm{Y}$ is a response. $\mathrm{A}, \mathrm{B}$, and $\mathrm{C}$ are the first, second, and third factor, respectively.

In this research, the null hypothesis $\left(\mathrm{H}_{0}\right)$ was there is no significant model between responses (TA, AA, CI, VI, and $\mathrm{BI}$ ) and three factors studied (addition of lime juice, the pretreatment of butterfly flower, and method of extraction). The significance level $(\alpha)$ set at 0.05 . Hence, the model stated as significant if $\mathrm{p}<0.05$.

The Design-Expert software was applied to test the models, select the best model, and set the best combination of factors to obtain a set of responses with certain criteria.

\section{RESULTS AND DISCUSSION}

Several preliminary studies conducted to obtain data needed to formulate the butterfly pea flower drinks. First, a hedonic scale with 30 panelists arranged to determine the preferred amount of lime juice. The preferred amount was $3.5 \mathrm{~g}$ lime juice per $125 \mathrm{ml}$ water. It was roughly about $1 / 2$ slice of lime with average size.

Second, the study to determine the weight of butterfly pea petals. The average weight of butterfly pea petals ( $\mathrm{n}$ $=100$ ) was $0.184 \mathrm{~g} \pm 0.033 \mathrm{~g}$. Applying 10 petals per 125 $\mathrm{ml}$ water is one of the common practices to serve butterfly pea drinks [10]. Total average weight of 10 petals was $1.85 \mathrm{~g}$. The average moisture content of the fresh petal was $89.50 \%$. Therefore, the weight of 10 petals on a dry basis was $0.1885 \mathrm{~g}$. The moisture content of dried petals was $22.42 \%$. To have the equal weight on a dry basis, $0.243 \mathrm{~g}$ dried petal per $125 \mathrm{ml}$.

\subsection{Selecting the Fittest Model for Color Quality}

A linear model with interaction between two factors was fit to describe the effect of pre-treatment (A) of butterfly pea petal, method of extraction (B), and added lemon $(\mathrm{C})$ to the color quality of butterfly pea drinks $(p<0.05)$ as shown in Table 1 . However, not all possible interactions showed a significant effect. For instance, 
interaction $\mathrm{AB}$ was insignificant to $\mathrm{VI}$ and $\mathrm{BI}$. Meanwhile, interaction AC gave no significant effect to

Table 1 Summary of the ANOVA for factorial model of color intensity (CI), violet index (VI) and browning index $(\mathrm{BI})$ of butterfly pea drinks.

\begin{tabular}{lrrr}
\hline \multirow{2}{*}{$\begin{array}{c}\text { Source of } \\
\text { Variation }\end{array}$} & \multicolumn{3}{c}{ p-Value } \\
\cline { 2 - 4 } & \multicolumn{1}{c}{ CI } & \multicolumn{1}{c}{ VI } & \multicolumn{1}{c}{ BI } \\
\hline Model & $<0.0001^{*}$ & $<0.0001^{*}$ & $<0.0001$ \\
A-Pre- & & & \\
treatment & $<0.0001^{*}$ & 0.1056 & 0.0004 \\
B-Extraction & $<0.0001^{*}$ & $<0.0001^{*}$ & 0.0002 \\
C-Lime & $<0.0001^{*}$ & $<0.0001^{*}$ & 0.274 \\
AB & $0.0109^{*}$ & 0.3059 & 0.149 \\
AC & 1 & 1 & 0.0404 \\
BC & $0.0024^{*}$ & $<0.0001^{*}$ & $<0.0001$ \\
\hline
\end{tabular}

$*$ Significant at $\alpha=0.05$

$\mathrm{CI}$ and VI. Interaction $\mathrm{BC}$ was significant to all color quality evaluated.

The most significant impact on the color quality easily seen was due to the addition of lime juice. The lime juice lowered the $\mathrm{pH}$ of the butterfly pea drinks, which shifted the color from blue to violet (Figure 1). As a result, both CI and VI decreased. CI is also significantly affected by the pre-treatment and the method of extraction (Figure 2). Among pre-treatment, PD gave the lowest CI.

The storage in the refrigerator for 48 hours (PR) caused the pale spots that were easily detected visually. The discoloration probably happened because the cold condition condensed the water vapor in the plastic packaging. Anthocyanin in butterfly pea flowers is a polar substance that is easily soluble in water droplets. Hence, some spots in the petals lose their color.

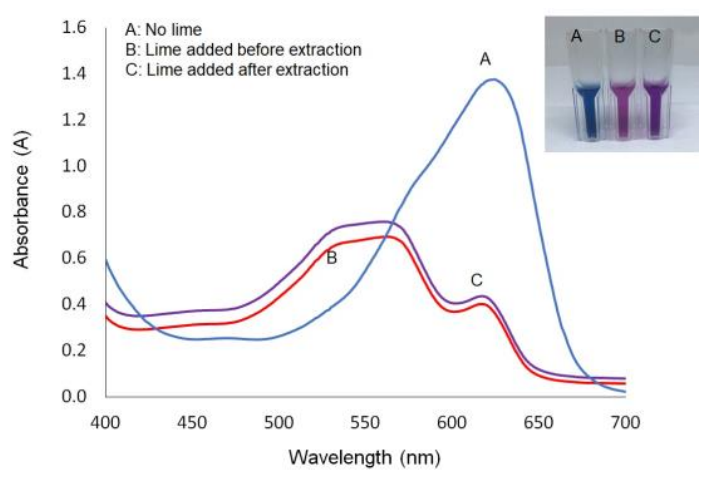

Figure 1 Color and spectrogram of butterfly pea drinks made by immersing $0.1885 \mathrm{~g}(\mathrm{db})$ fresh butterfly pea petal in $125 \mathrm{ml}$ hot water $\left(100^{\circ} \mathrm{C}\right)$ for 15 minutes with and without the addition of $3.5 \mathrm{~g}$ lime juice.
Extraction method gave a bigger effect on CI than the pre-treatment. Among the methods of extraction, ED
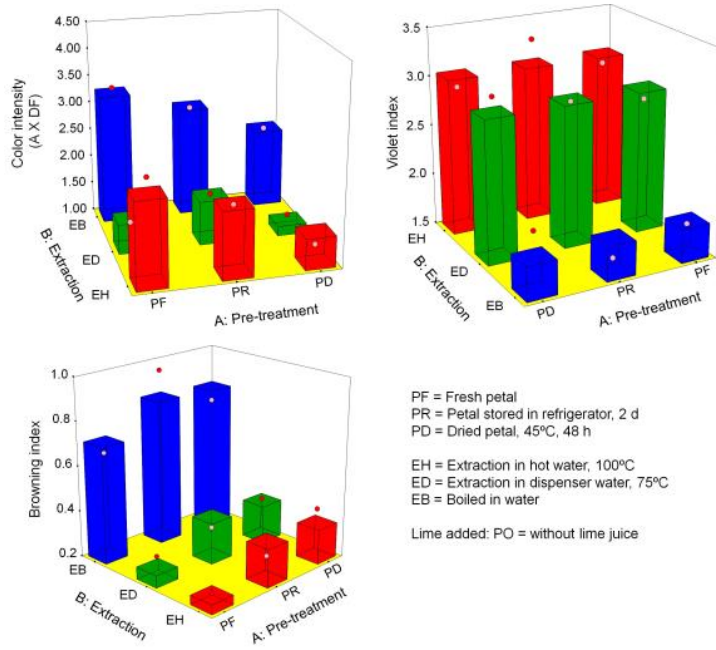

$E H=$ Extraction in hot water, $100^{\circ} \mathrm{C}$ $E M=E$ Extraction in dispenser water, $75^{\circ} \mathrm{C}$
$E B=$ Boiled in water
$E B$.

Lime added: $P O=$ without lime juice

Figure 2 Color quality (color intensity - CI, violet index - VI, and browning index - BI) of butterfly pea drinks made of $0.1885 \mathrm{~g}(\mathrm{db})$ butterfly pea petal as the effect of pre-treatment of butterfly pea petal and method of extraction.

resulted in the lowest CI. Meanwhile, the highest CI resulted from EB.

\subsection{Selecting the Fittest Model for Functional Properties}

A linear model with interaction between two factors was also the fittest model to describe the effect of all factors studied to the functional properties (TA and AA) of butterfly pea drinks (Table 2 ). All possible interactions were significant $(\mathrm{p}<0.05)$. 
Similar to CI, the TA was mostly affected by the extraction method. ED the lowest, while EB the highest (Figure 3A). The similarity is plausible because the color of the butterfly pea drinks came from the anthocyanin. The highest $\mathrm{CI}$ and TA in EB clearly explained that

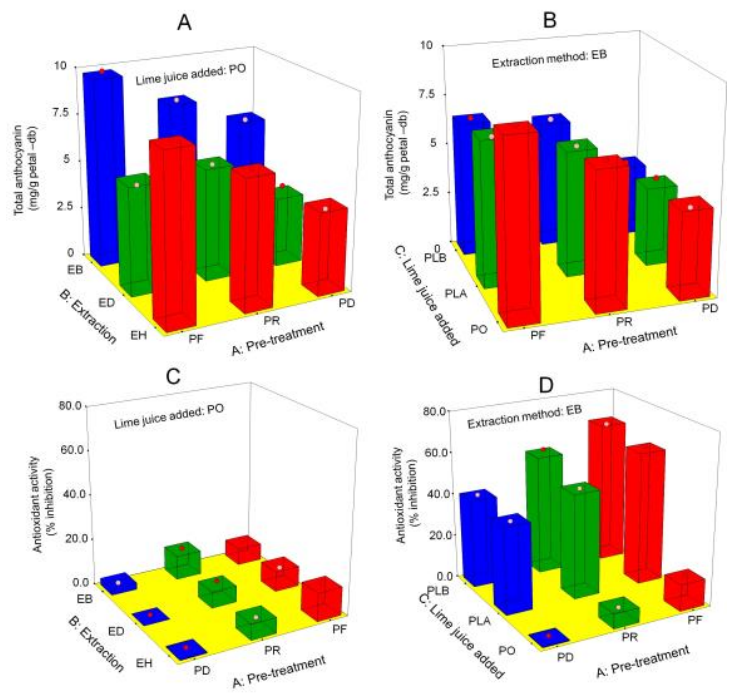

Figure 3 Total anthocyanin (A and B) and antioxidant activity (C and D) of butterfly pea drinks of $0.1885 \mathrm{~g}(\mathrm{db})$ as the effect of method pretreatment vs pretreatment and pre-treatment vs lemon juice added.

higher temperature is more effective to extract the anthocyanin from butterfly pea, and the anthocyanin in butterfly pea is relatively stable in high temperature.

Among the pre-treatment PD resulted in the lowest TA (Figure $3 \mathrm{~A}$ and Figure 3B). There were two possibilities for this result. First, the dried natural matrix created an extra barrier to water to extract the anthocyanin from vacuoles. Second, the anthocyanin content decreased due to the heat exposure for 48 hours during storage. The loss of bioactive compounds including anthocyanins, during drying are reported by several studies $[6,7]$.

Both butterfly pea flower and lime are sources of antioxidants. Butterfly pea flower could be stated for having antioxidant activity due the presence of anthocyanin based on its basic compound structural orientation. The ring orientation determines the anthocyanin capacity for binding with the unpaired electron as well as which atom from the hydroxyl group that will be donated to the free radicals. The aglycon of anthocyanin in butterfly pea is delphinidin, which has more hydroxyl number than other aglycon. The greater number of hydroxyl groups tend to have greater antioxidant activity [14]. Lime is one of the citrus fruits that rich sources of useful phytochemicals, such as ascorbic acid and flavonoids. Ascorbic acid is one of the most famous antioxidants. The flavonoids compound called hesperidin that contains lime have a direct role for scavenging the reactive oxygen species (ROS) [15].

Figure $3 \mathrm{C}$ shows the antioxidant activity of butterfly pea made with no addition of lime (PO). All combinations of pre-treatment and extraction methods resulted in relatively low AA with the \% inhibition lower than $20 \%$. In contrast, as seen in Figure 3D, the addition of lime juice extremely increased the AA. The highest antioxidant activity reached more than $70 \%$ inhibition.

The figure depicted the antioxidant activity of butterfly pea drinks mostly contributed by the lime juice with the possibility of synergetic effect between phytochemicals in lime juice and in butterfly pea petals.

\subsection{Selecting the Best Process}

This research established the fittest model of color quality and functional properties of butterfly pea drinks, with the pre-treatment, method of extraction and lime addition as the variables. Through the model, the set of variables may be determined to fit the targeted criteria. In the case of butterfly pea drinks as a functional beverage, the functional properties are more important than the color quality.

Correlation between total anthocyanin and antioxidant activity was low (Pearson correlation coefficient, $r<0.15)$. As stated before, the antioxidant activity of the butterfly pea drinks mainly contributed by the lime juice added, regardless of the total anthocyanin. Therefore, there were two selected procedures. First, the procedure to obtain maximum anthocyanin. Second, the procedure to gain highest antioxidant activity.

The first procedure was $0.1885 \mathrm{~g}(\mathrm{db})$ fresh petal boiled in $125 \mathrm{ml}$ water for 15 minutes with no lime

Table 2 Summary of the ANOVA for factorial model of total anthocyanin (TA) and antioxidant activity (AA) of butterfly pea drinks

\begin{tabular}{lcc}
\hline \multirow{2}{*}{$\begin{array}{c}\text { Source of } \\
\text { Variation }\end{array}$} & \multicolumn{2}{c}{ p-Value } \\
\cline { 2 - 3 } MA & AA \\
\hline Model & $<0.0001^{*}$ & $<0.0001^{*}$ \\
A-Pre-treatment & $<0.0001^{*}$ & $<0.0001^{*}$ \\
B-Extraction & $<0.0001^{*}$ & $<0.0001^{*}$ \\
C-Lime & $0.0014^{*}$ & $<0.0001^{*}$ \\
AB & $0.0003^{*}$ & $0.0331^{*}$ \\
AC & $0.0104^{*}$ & $0.0041^{*}$ \\
BC & $0.0177^{*}$ & $0.0010^{*}$ \\
\hline
\end{tabular}

* Significant at $\alpha=0.05$

added. The second procedure was $0.1885 \mathrm{~g}(\mathrm{db})$ fresh petal boiled in $125 \mathrm{ml}$ water for 15 minutes with the addition of $3.5 \mathrm{~g}$ lime juice before boiling/extraction. 
By following the first procedure, the predicted value (95\% prediction interval) of CI, VI, BI, TA, and AA were 2.90-3.72, 1.56-2.13, 0.56-0.88, 9.01-10.52 mg/g db, 1.46-13.61\% inhibition, respectively. Meanwhile, the predicted value of CI, VI, BI, TA, and AA of butterfly pea drinks made by second procedure were 2.73-3.55, $0.75-1.33,0.17-0.49,8.26-9.77 \mathrm{mg} / \mathrm{g} \mathrm{db}, 70.33-82.49 \%$ inhibition. The antioxidant activity resulting from the first procedure was quite low, while the anthocyanin content yielded by the second procedure was relatively high. In addition, the second procedure showed better color quality by appearing lower in the browning index. Therefore, the second procedure was more recommended.

\subsection{The Effectivity of Extraction}

Five replications of total anthocyanin analysis showed that the anthocyanin content was $1.09 \pm 0.36$ $\mathrm{mg} / \mathrm{g}$ fresh petal (wb) or equal to $10.34 \pm 3.43 \mathrm{mg} / \mathrm{g}$ fresh petal $(\mathrm{db})$. The predicted mean of the anthocyanin resulting from the first and second recommended procedure was 9.77 and $9.02 \mathrm{mg} / \mathrm{g}$ of fresh petal $(\mathrm{db})$. Thus, both procedures were effective to extract the anthocyanin in butterfly pea petals by extracting $94.49 \%$ and $87.23 \%$ of total anthocyanin, respectively.

In the previous research maceration of $4 \mathrm{~g}$ butterfly pea petals in $250 \mathrm{ml}$ hot water $\left(100^{\circ} \mathrm{C}\right)$ for 30 minutes was applied. The procedure resulted in $1.22 \pm 0.07 \mathrm{mg}$ anthocyanin/g fresh petal (wb) [10]. However, the study expressed anthocyanin as cyanidin 3-glucoside, while in this research anthocyanin was calculated as delphinidin 3 -glucoside. In addition, in the previous research, the moisture content of the petal was not stated. Using the moisture content of the petal in this research, the anthocyanin content from the previous procedure on a dry basis was equal to $11.93 \pm 0.68 \mathrm{mg}$.

\section{CONCLUSION}

This research established three variables to yield the highest anthocyanin content and antioxidant activity in butterfly pea drinks. The fresh petal was the best, compared to the petal refrigerated for two days and dried petal. Applying relatively high temperatures in relatively short time essentially contributed to the effectiveness of anthocyanin extraction, while the addition of lime juice predominantly affected the antioxidant activity.

The recommended procedure to gain highest antioxidant activity and relatively high anthocyanin in butterfly pea drink is (a) add $3.5 \mathrm{~g}$ lime juice to $125 \mathrm{ml}$ of drinking water, (b) raise the temperature of water to the boiling point, (c) boil the $0.1885 \mathrm{~g} \mathrm{(db)} \mathrm{fresh} \mathrm{petal} \mathrm{for} 15$ minutes. After the extraction, separate the filtrate from the residual petal.
The procedure resulted in a deep purple drink (color intensity 2.73-3.55 and violet index 0.75-1.33) with relatively low browning index (0.17-0.49). The predicted anthocyanin content of the drink was $8.26-9.77 \mathrm{mg} / \mathrm{g} \mathrm{db}$, while the antioxidant activity was $70.33-82.49 \%$ inhibition. Assuming the serving size of the drink is 250 $\mathrm{ml}$, the anthocyanin content per serving was equal to 3.11 to $3.68 \mathrm{mg}$.

Further study is needed to explore the wide range of methods of serving butterfly pea drinks. For instance, the cold brewing and the addition of herbs like ginger, lemongrass and cinnamon.

\section{REFERENCES}

[1] M. Marpaung, "Tinjauan manfaat bunga telang (clitoria ternatea 1.) bagi kesehatan manusia," Journal of Functional Food and Nutraceutical, vol. 1, no. 2, pp. 1-23, 2020

[2] K. Kazuma, N. Noda and M. Suzuki, "Malonylated flavonol glycosides from the petals of Clitoria ternatea," Phytochemistry, vol. 62, p. 229-237, 2003.

[3] K. Kazuma, N. Noda and M. Suzuki, "Flavonoid composition related to petal color in different lines of Clitoria ternatea," Phytochemistry, vol. 64, p. 1133-1139, 2003.

[4] M. M. Ramirez-Rodrigues, M. L. Plaza, A. Azeredo, M. O. Balaban and M. R. Marshall, "Physicochemical and Phytochemical Properties of Cold and Hot Water Extraction from Hibiscus sabdariffa," Journal of Food Science, vol. 76, no. 3, pp. C428-C435, 2011.

[5] B. C. Wang, R. He and Z. M. Li, "The Stability and Antioxidant Activity of Anthocyanins from Blueberry," Food Technology and Biotechnology, vol. 1, pp. 42-49, 2010.

[6] Dey, S. Bhattacharyya and T. K. Pal, "Antioxidant Activities of Moringa concanensis Flowers (fresh and dried) Grown in West Bengal," International Journal of Research in Chemistry and Environment, vol. 4, no. 3, pp. 64-70, 2014.

[7] S. Heydari, R. Rezaei and G. H. Haghayegh, "Effect of Drying Processes on Stability of Anthocyanin Extracts from Saffron Petal"," Evolving Trends in Engineering and Technology, vol. 2, pp. 13-18, 2014.

[8] M. Marpaung, N. Andarwulan, P. Hariyadi and D. N. Faridah, "The Difference in Colour Shifting of Clitoria ternatea L. Flower Extract at pH 1, 4, and 7 during storage," Current Nutrition and Food Science, vol. 15, no. 7, pp. 694-699, 2019. 
[9] L. Rodriguez-Fragoso, J. Reyes-Esparza, S. W. Burchiel, D. Herrera-Ruiz and E. Torres, "Risks and benefits of commonly used herbal medicines in Mexico," Toxicology and Applied Pharmacology, vol. 227, no. 1, pp. 125-35, 2008.

[10] A.M. Marpaung and S. Chiang, "The Appropriate Way to Serve Butterfly Pea Flower Drinks at Home," in International Conference on Innovation, Entrepreneurship and Technology, Tangerang, 2018.

[11] M. Marpaung, N. Andarwulan, P. Hariyadi and D. N. Faridah, "Thermal Degradation of Anthocyanins in Butterfly Pea (Clitoria ternatea L.) Flower Extract at pH 7," American Journal of Food Science and Technology, vol. 5, no. 5, pp. 199-203, 2017.

[12]P. S. Vankar and J. Srivastava, "Evaluation of Anthocyanin Content in Red and Blue Flowers," International Journal of Food Engineering, vol. 6, no. 4, p. Article 7, 2010.

[13] M. Marpaung and K. H. Tjahjadi, "The Analysis of Monomeric Anthocyanin by $\mathrm{pH}$ Differential Method Is Not Appropriate for Certain Anthocyanins," in Proceedings of the 16th ASEAN Food Conference (16th AFC 2019) - Outlook and Opportunities of Food Technology and Culinary for Tourism Industry, Ternate, 2019.

[14] Miguel and M. G, "Anthocyanins: Antioxidant and/or anti-inflammatory activities," Journal of Applied Pharmaceutical Science, vol. 01, no. 06, pp. 07-15, 2011.

[15]Z. Zou, W. Xi, Y. Hu, N. Chao and Z. Zhou, "Antioxidant activity of Citrus fruits," Food Chemistry, vol. 196, pp. 885-896, 2016. 